\title{
HUMAN RIGHTS VIOLATION: ITS IMPACT ON THE MENTAL \\ WELL-BEING OF LGBTI STUDENTS IN A SOUTH AFRICAN \\ RURAL-BASED UNIVERSITY
}

\author{
A. H. Mavhandu-Mudzusi* \\ e-mail:mmudza@unisa.ac.za \\ P. T. Sandy* \\ e-mail: sandypt@unisa.ac.za \\ *Department of Health Studies \\ University of South Africa \\ Pretoria, South Africa
}

\section{ABSTRACT}

This article reports on human rights violation, and its impact on the mental well-being of lesbian, gay, bisexual, transgender and intersex students in a South African rural-based university. A qualitative multi-method approach was adopted, underpinned by interpretative phenomenological analysis. Data were collected using semi-structured individual interviews $(\mathrm{N}=20)$ and focus group interviews $(n=4 \times 5)$. The data were analysed thematically using interpretative phenomenological analysis. The results of the study indicate that university employees and heterosexual students violate lesbian, gay, bisexual, transgender and intersex students' human rights. Violation of the Human Rights has implications for the mental well-being of the studied population.

Keywords: human rights, mental well-being, non-heterosexual, phenomenology, university, students

\section{INTRODUCTION}

Every human being deserves to be treated with respect and dignity. This is what is referred to as human rights (Human Rights Act 1998). However, not all humans are treated this way. For example, attitudes toward people with mental health problems, and lesbian, gay, bisexual, transgender and intersex (LGBTI) are generally negative in many communities in the universe (Sandy and Shaw 2012).

Debates on the rights of LGBTI communities have been going on for decades in many parts of the world (Lannutti and Lachlan 2007; Mwamba 2009). These discussions are functions of the increasing awareness to demonstrate social inclusion and acceptance for nonheterosexual individuals, as they sometimes experience prejudice and discrimination in their communities (Ould and Whitlow 2011). Lesbian, gay, bisexual, transgender and intersex 
individuals are frequently exposed to victimisation, including rejection, physical assault and sometimes murder (Ould and Whitlow 2011; Mavhandu-Mudzusi 2014). These experiences may not only lead to isolation and withdrawal, but they may also result in this population to sometimes hide and deny their sexual orientations (Hyayambwa 2012; Mavhandu-Mudzusi 2014). In Zimbabwe, for instance, non-heterosexual relationships are considered immoral, criminal and deviant, and they are often criticised in public by religious and political leaders (Mabvurira et al. 2012). As a result, LGBTI people in Zimbabwe often hide their sexual orientations and deny the same when questioned (Mabvurira et al. 2012). This is also the case for other countries in Southern Africa, like South Africa, where LGBTI individuals may sometimes hide their sexual orientations because of fear of prejudice and discrimination (Mavhandu-Mudzusi 2014). Such reactions to prejudicial and discriminatory acts may lead to long term stress, which in turn may contribute to the development of mental health problems in this population (Meyer, Dletrich and Swartz 2008). In spite of this, there is a distinct paucity of empirical literature on human right violation and mental health problems among LGBTI individuals in Southern Africa.

\section{BACKGROUND AND LITERATURE REVIEW}

The term mental health refers to a state of emotional, psychological, and social well-being in which people can cope with the normal stresses of life, and contribute to their communities (Sandy and Rioga 2012). This suggests that people may develop mental health problems when their emotional, psychological, and social well-being is disrupted through exposure to stress evoking events. Mental health problems are the human sufferings or distress that disrupt people's lives and subsequently bring them into contact with mental health services (Sandy and Rioga 2012). Examples of these may include insomnia, suicidal ideations, and paranoia.

Mental health problems are prevalent among the lesbian, gay, bisexual, transgender and intersex people. This population suffers from more mental health problems relative to their heterosexual counterparts (Riggle et al. 2005). Examples of mental health problems, which this population often experience, include anxiety, suicidal ideations and self-harming behaviours. Suicidal attempts and successful suicides are not uncommon among LGBTI people, with the prevalence of the latter ranging from 11 per cent to 42 per cent (Consolacion, Russel and Sue 2004). Despite these tragic outcomes and pervasive mental health problems among LGBTI people, attitudes toward them are still largely negative in many regions of the world (Saucier and Cawman 2004). Violence and hate crimes against LGBTI individuals are commonly in both developing and developed countries (Moskowitz, Rieger and Roloff 2010). However, violence 
and hate crimes against this population are seen more in developing than developed countries. For example, Nigeria and Zimbabwe, have anti-LGBTI legislations and religious and cultural practices that promote discrimination and prejudice toward LGBTI individuals (Mudavanhu 2010).

Negative regard from others in the form of stigmatisation, prejudice and discrimination can lead to negative self-regard, which clinicians in mental health settings frequently refer to as internalised homophobia or sometimes as internalised homonegativity (Morris et al. 2001). In relation to LGBTI, this term refers to an active process of directing negative social attitudes toward the self, leading to a devaluation of the self and resultant intrapersonal conflict and poor self-image (Meyer 2007). Outcomes of range of research studies revealed positive and direct relationships between internalised homophobia, self-harm, suicidal ideations, and anxiety symptoms (Mavhandu-Mudzusi 2014; Mavhandu-Mudzusi and Sandy 2015). Thus, LGBTI individuals are considered a high-risk group for mental health problems. Taking this into account, governments of some countries, for example, the United Kingdom, Australia, and South Africa, developed laws and policies to safeguard the Human Rghts of LGBTI individuals, and promote social inclusion and societal acceptance of this population (Human Rights Watch 2011).

South Africa is the first country in Africa, and one of the few in the world with legal frameworks that seek to protect the equality and rights of LGBTI people. Its 1996 Constitution prohibits discrimination based on sexual orientation (Epistein, Flynn and Telford 2003). In spite of this, LGBTI people still face discrimination and violence, especially in rural areas, including the university communities. LGBTI students in rural universities often experience violence because of their of their sexuality (Mudavanhu 2010). As a result, they sometimes terminate their education to avoid repetition of violent encounters. Exposure to such discriminatory experiences is a violation of people's right to safety and education. This indicates that the principle that no person should be discriminated against, regardless of his/her sexuality, highlighted in the 1996 Constitution, do not reflect the attitudes of most South Africans toward the LGBTI community. Yet studies that explore attitudes toward LGBTI persons in South Africa, including violation of their Human Rights, are rare. To date, there are no published empirical studies in South Africa on LGBTI individuals in rural-based universities in relation to violation of human rights, and the impact of this on their mental health. It is precisely these issues that this study seeks to respond to within the context of university students of a ruralbased university. 


\section{METHODS}

\section{Design}

To date, less empirical attention has been directed towards examining the Human Rights of LGBTI individuals and how violation of these may undermine positive mental health. Phenomenological methodologies are considered effective for studying under researched and poorly understood phenomena (Smith, Flowers and Larkin 2009). Following a comparative examination of the empirical literature sources on the variants of phenomenology, this study opted for interpretative phenomenological analysis (IPA) and utilised it both as a design and as a tool of analysis. This strand of phenomenology requires the researcher to go beyond the description of phenomena, reporting not just what participants' state about their experience, but also offering expert analysis of these experiences. Adopting this double hermeneutic approach can generate comprehensive insights into LGBTI people, including their Human Rights and the impact of violating those rights on LGBTI persons. Such understanding was achieved in the context of a rural-based university in South Africa, a view that is consistent with one of the principles of IPA. This phenomenological approach recognises that the meanings people attribute to experiences can be understood in the socio-cultural contexts in which they are experienced (Langdridge 2007).

\section{Sampling and recruitment}

This study was conducted at a rural-based university situated in one of the poorest provinces of South Africa (Dorington et al. 2006). The university had a student population of 10,000 at the time the study was conducted. Most of the students were from other poor provinces of South Africa, and some were from other countries in the Sub-Saharan Africa region, like Zimbabwe (Patel, Buss and Watson 2003). Following ethical clearance and managerial permission to conduct the study, participants were identified and recruited for participation.

The university has an HIV/AIDS unit that offered testing service and psychological support to students. During their visits to this unit, students are requested to complete a Voluntary Counselling and Testing (VCT) questionnaire developed by the Higher Education HIV/AIDS Programme. This questionnaire has specific questions that assisted the researchers to identify non-heterosexual students, in order words, LGBTI individuals.

Two sampling approaches were employed in this study, convenient and snowballing. Each LGBTI student identified during the visit to the HIV/AIDS unit was given an information sheet that contained the aim, inclusion criteria and benefits of the study. Students who were prepared 
to participate were encouraged to complete a consent form. These students also encouraged other LGBTI students to contact the researchers. The students made contact with the researchers and were invited to the HIV/AIDS unit for an explanation of the study and to request their permission for participation. A total of 20 LGBTI students, with ages ranging from 19 to 25 years, were recruited and participated in the study. This study sample comprised of five lesbians, five gays, four bisexuals, three transgender and three intersex students.

\section{Data collection}

Informed consent was sought and obtained from each participant before data collection. Data were collected in two phases between March and May in 2012 using a semi-structured interview schedule designed in line with IPA guidelines (Smith 2005). This meant that the interview schedule, which guided the course of the interviews included prompts and open questions to enable participants to freely discuss issues related to violation of human rights and the consequences of this.

Phase one of the data collection involved individual interviews $(n=20)$, while phase two utilised four focus group interviews, each of which comprised five participants $(n=4 \times 5)$ of diverse gender and sexual orientation. The essence of the focus group interviews was to explore and clarify issues not fully discussed in the previous set of interviews. The focus groups interviews followed standard guidelines and were conducted by one of the authors, and a research assistant who served as an additional data source and made notes of observations during interviews. All interviews were audio-recorded and to ensure privacy, they were held in a designated room in the HIV/AIDS unit. Each interview lasted for 55 minutes to an hour. At the end of each interview, some time was spent debriefing participants. They were encouraged to talk about their experiences of the interviews, and their feelings of being interviewed about their Human Rights and sexuality.

\section{Data analysis}

The audio-recorded interviews were transcribed verbatim into textual materials that were manually and independently analysed by the two researchers using Smith`s (2005) IPA approach to analysis. Analysis proceeded in parallel with the interviews, and was conducted iteratively throughout the interview period until category saturation was achieved. The analysis was carried out in stages for each transcript. These consisted of reading and re-reading transcripts, followed by making notes and the development of emergent themes. Connection between emergent themes was explored and related themes were clustered, resulting in the 
development of superordinate themes. The outcomes of this approach was the formation of a master list of themes for each transcript containing superordinate themes, sub-themes and associated quotes to illustrate where in the transcripts the themes could be found. The master lists of themes were compared and similarities examined. The outcomes of this were separate single master lists of themes for both sets of interviews, individual and focus groups.

\section{Rigour}

Rigour is a measure of the overall quality of research, reflected in the data collection and analysis processes (Macnee and McCabe 2008). A range of guidelines is available for ensuring rigour of qualitative research. This study adopts Guba and Lincoln's (1994) framework of trustworthiness, as it fits in well with the qualitative world of multiple realities and ways of knowing. It includes five criteria; credibility, dependability, confirmability, transferability and authenticity.

Notes were taken during interviews to ensure dependability and confirmability. A sample of the audio-recorded data was independently transcribed and analysed by the two researchers for confirmability reasons. Both researchers agreed on the outcome of their analysis. Rigour was further enhanced by member checking and validity checks to enhance the credibility and dependability of the study outcomes. With regard to the former, transcripts were sent to some participants to determine their accuracy and in all cases participants were satisfied. Validity checks on the master list of themes were carried out by a third researcher to ensure that the themes were relevant and evidenced in the data.

\section{Ethical considerations}

Ethics approval to undertake the study was sought and obtained from the Research Ethics Committee of the study site; a rural-based university. Permission to collect data was obtained from the Management Team of the Research Site. Both verbal and written consent were obtained from each participant before interview. Confidentiality and anonymity were also respected throughout the study. Participants were free to withdraw from the study at any time. All data were stored securely in accordance with the privacy and data collection laws.

\section{RESULTS}

Two superordinate themes emerged from the data analysis; 'violation of human rights' and 'Impact on mental well-being'. These themes contained a number of sub-thematic categories indicated in bold italics. Extracts from participants` narratives are used to support the 
discussions of identified themes. The initials 'In' and 'Fg' identify data from individual and focus group interviews respectively.

\section{Violation of human rights}

This theme relates to the categories of human rights violated and discussions of participants` narratives of the processes of how their rights were violated. A commonly held opinion of all participants was that everybody has the right to effective education and no person should be denied of this. However, most participants reported that higher education employees, including lecturers, generally violated LGBTI students’ rights to education. These participants provided their experiences of stigmatisation and discrimination in the classrooms.

Lecturers refer to homosexuality as sin. People of this sexuality, including myself, are usually ignored and not given the chance to participate in class (In).

Concerns were expressed by some participants about limited classroom participation, as they claimed it could lead to low educational achievement. Concerns were also repeatedly raised about restricted access to financial assistance. This is a violation of the right to equality. Some participants asserted that LGBTI students were sometimes not offered equal access to financial support relative to their heterosexual counterparts.

The last straw that breaks the camel`s back was when I was denied an application form for financial aid because of my sexuality. I terminated my education. (Fg).

Failure to offer financial support to students from poor socio-economic backgrounds, participants asserted, may result in termination of training. They attributed this to limited funds or lack of it, to pay for tuition and accommodation. In addition to this, termination of training may also be a function of LGBTI students `reluctance or refusal to seek financial assistance for fear of further sexual prejudice and discrimination, which some participants considered insulting and dehumanising.

For some participants, reluctance to attend classes or termination of training can be attributed to anxieties relating to issues of not feeling safe on the university campus. For most part, they believed that LGBTI students are at increasing risk in South African rural-based universities of being physically assaulted, sexually harassed and exposed to homophobic remarks from lecturers and other staff.

You gay, you are a demon. Do you know that? You are demon possessed. If I find you outside this campus, I will behead or stone you to death. (Fg). 
The majority of participants claimed that LGBTI students were often exposed to persecutory and murder threats, and occasionally they may have their property stolen or intentionally damaged. They were sometimes subjected to rape, an act that was frequently referred to by some participants as 'corrective rape' because of the perceived urgency to change LGBTI students`s sexual orientation. A minority of participants reported that these experiences might result in LGBTI students expecting to be discriminated against, and thus often isolate themselves. These participants therefore coined the term 'dreams come true' that relates to frequent encounter of discriminatory experiences

My colleagues have refused to play tennis and netball with me on many occasions. In one instance, it was the referee who told me that I was not eligible to play netball. (In)

All participants talked about issues of eligibility to partake in activities. They unanimously reported that being LGBTI is a criterion for exclusion from social activities and association with heterosexuals. A minority of participants stressed that it is also a criterion for stalking, a behaviour that violates or invades people's privacy. They reiterated on several occasions that LGBTI students are often perceived by their heterosexual counterparts, including university employees, as lesser human beings and infected with contagious diseases.

We are treated like it is a disease; people do not want us to be next to them. For example, if you sit next to them, they will just stand up and leave you alone. (Fg).

Expression of these attitudes is an indication of disrespect and unwillingness to accept and socially include LGBTI individuals in university communities. It is therefore not surprising for all participants to accept that LGBTI students are in the main denied their choice of university facilities, such as accommodation.

I am a male to female transgender. I was evicted from the female hostel because of my sexuality. It was tough, extremely frustrating at the time (In).

All participants, except for one, talked about their experiences of being denied of their choices of social events and the negative emotions like anger and frustration it generated in them. Another issue that was closely associated with denial and discussed by most participants relates to restricted visibility and access to healthcare.

As LGBTI students, we should make ourselves known. But the university management team are not supportive. It denied us the opportunity to hold LGBTI awareness seminars. It also denied us healthcare and information related to this. (Fg).

Sexual prejudice and discrimination when experienced over a protracted period of time can 
result in chronic stress, which in turn might negatively impact on individuals' mental wellbeing.

\section{Impact on mental well-being}

This theme concerns the impact of the violation of the Human Rights of LGBT students, including the prejudicial and discriminatory processes involved on the mental well-being of this population. There was a general agreement among participants that feelings of anger and frustration are normal reactions to prejudicial and discriminatory acts. These acts were therefore described by most participants as primary stressors for LGBTI students.

Being discriminated and prejudiced based on my sexuality make me feel angry and frustrated. Unfortunately, I have not created myself, so I cannot even change who I am. (In).

Some participants were therefore concerned that LGBTI students are at risk of excess mental distress because their Human Rights, such as those which relate to association and visibility are frequently violated. Few participants highlighted that the sexual activities of LGBTI students were often devalued and even condemned by the majority of students and academic staff around them. These participants claimed that prejudicial encounters of this nature generate fear and anxiety, which in turn might lead LGBTI students making attempts to hide or conceal their sexual preferences.

Because of fear of physical attack both at school and at home, we (lesbian students) end up dating boys so that people can stop talking about us. (Fg).

Some participants were of the view that this manner of addressing problems with discrimination and prejudice is an unpleasant place to be, a private hell, a view that is attributable to the burden involved in the constant preoccupation with concealment.

We have to constantly be on our guard, monitor how we speak, walk and dress. We also have to limit our friends to avoid being identified. (Fg).

A minority of participants believed that successful attempts at concealment or deception might lead LGBTI students to experience feelings of guilt, inferiority and hopelessness.

Lying to be heterosexual makes others and me inferior, makes us feel like lesser persons. I guess we have to lie to be accepted as well as to prevent attacks. This sometimes makes us think of hurting and ending our life. (Fg).

Suicidal feelings are not uncommon among stigmatised and minority groups, like LGBTI individuals. Some participants reported their personal accounts of self-harm and attempted 
suicide, which they claimed were triggered by labelling and stigmatisation as well as violent attacks for not conforming to the majority norm of heterosexual standards. According to these participants, LGBTI students are often ascribed derogatory labels, such as sinners and demons.

Some people refer to us as sinners, some as devils and some as Satan. I must say that I sometimes think that I have sinned for being a gay and perceived my sexuality as abnormal. (Fg).

Labelling and stigmatisation or negative regard from others can lead to negative self-regard or negative self-perception and development of other signs and symptoms of mental distress, like substance use and misuse. Participants of this study echo these issues.

Labels generate feelings of humiliation and loss of hope in us. The labels make me feel hopeless and helpless. I drink alcohol to cope with these emotions. (In).

\section{DISCUSSION}

The violation of the Human Rights of LGBTI students of a rural-based university in South Africa is noticeable, particularly in terms of safety, association, education, expression, privacy, and visibility. This study reported these rights to be repeatedly and frequently violated by heterosexual students and university employees, including academic staff. For example, participants claimed that LGBTI students' requests for recognition to enhance awareness or visibility were rejected on several occasions by both the university management team and academic staff. Worrying experiences of discrimination against LGBTI students, such as being ignored when expressing concerns of threats and actual violence and being mocked in class rooms by academic staff, were also reported by a significant number of participants. While the adoption of such attitudes indicates disrespect and unwillingness to offer support to LGBTI students, it also indicates violation of a critical aspect of the 1996 Constitution of South Africa that advocates equality and respect for the Human Rights and freedom for all South Africans (Epistein, Flynn and Telford 2003). The question now arises, why are lecturers, who are believed to be knowledgeable, failing to adhere to this provision of the Constitution?

Religious and cultural beliefs are among some of the explanations for the violation of the Human Rights of LGBTI students. It is critical to mention that people do not live in isolation, but live in relation to one another. Academic personnel in rural settings are members of communities served by their respective universities. Acceptance in these communities or social groups, including continued memberships are generally influenced by adherence to community normative beliefs (Hogg and Terry 2000). In relation to sexuality, rural communities in South Africa promote, in the main, heterosexual relationships. This means that relationships other than heterosexual are condemned outright and perceived as taboos and barbaric in these 
settings. From a religious point of view, these relationships are described by community members as satanic and demonic (Mavhandu-Mudzusi and Sandy 2015). Because academic staff identify with their communities, it was not surprising for participants of this study to report that the academic staff often use negative descriptors or labels, such as sin, demons and barbaric to refer to LGBTI students. Acknowledging this, communities have a role in influencing people's attitudes, its development and enhancement. But, the degree of influence is dependent on the strength of identification with communities (Hogg and Terry 2000). So, the more people identify with a community, the more they will express behaviours that are congruent with their community's beliefs.

Human rights abuses of LBGTI students are pervasive in higher education institutions in South Africa. Instances of stalking, rejection, rape, sexual harassment and punishment have been reported in the literature (Arndt and De Bruin 2006). While these outcomes of abuses are echoed in this study, they are mainly carried out by academic staff and heterosexual students. For instance, participants reported that LGBTI students' attempts to participate in sports were generally rejected. They also reported limited opportunities to actively engage in classroom discussions and denial of appropriate accommodation. Because of the consistency and frequency in the violation of the Human Rights of this population, the issue of equal rights and freedom for all South Africans seems to be more of a vision that is yet to be achieved. Added to this, the consistency in the violation of LGBTI students' Human Rights underscores the ongoing challenges to the mental well-being faced by this population in rural communities.

The roots of mental health problems which LGBTI students face are the stresses generated from the discriminatory and prejudicial experiences they are exposed to. These experiences do not only indicate the university community's lack of understanding of LGBTI students, but they also point to serious health implications. Taking for instance the possibility of rape, in addition to the risks of contracting sexually transmitted infections, like the human immuno-deficiency virus (HIV), victims may also be exposed to the risk of psychological trauma. Thus, LGBTI individuals who have experienced discrimination and prejudice because of their sexuality may adopt approaches to conceal their sexual orientation in order to prevent a repeat of negative consequences. In this study, participants reported that lesbian or transgender students dated males, and restricted their socialisation to only a few friends to avoid identification of their sexual orientation. Concealment of any kind, especially in the context of sexuality, may have a paradoxical effect of leading to feelings of guilt, inferiority, anxiety and hopelessness (Sandy 2013). This is because of the constant preoccupation with hiding. Because concealment promotes sharing of sexual partners, it may lead to an increase in incidence and prevalence of 
HIV and conflicts among LGBTI students, which in turn may lead to symptoms of mental distress, such as self-harm and suicide attempts. It is therefore not a surprise for participants of this study to describe this hiding process as a 'private hell' and an 'unpleasant place to be' that requires delicate handling.

\section{(Processes of} Violation)

- Stigmatisation

- Discrimination

- Prejudice

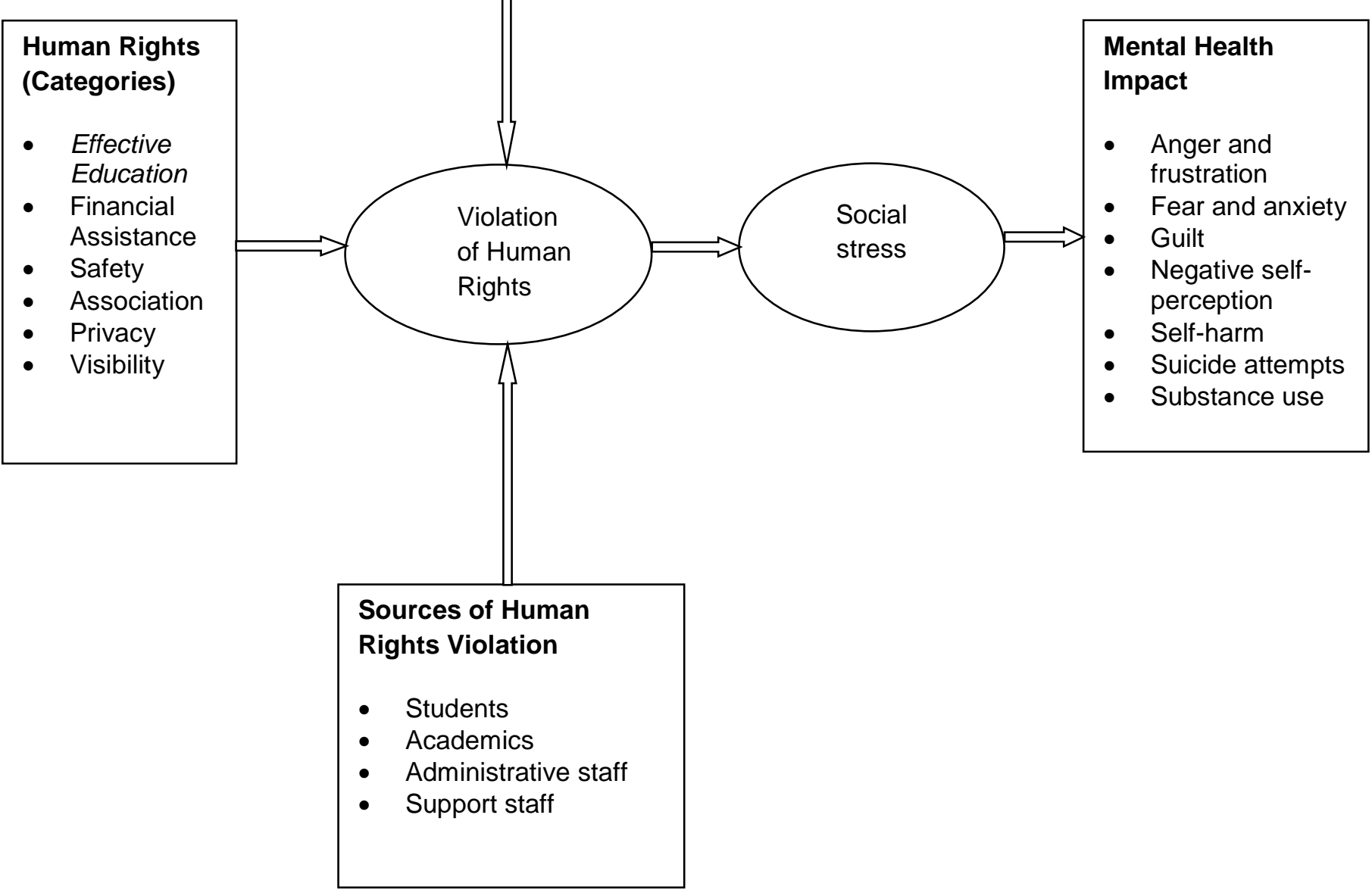

Figure 1: Rights-Impact Model.

Taking into account the unpleasantness of concealment, people may at some point find it unbearable and may thus engage in identity awareness approaches to alleviate their distress. Participants' attempts at raising LGBTI awareness at the university campus were rejected by its management team and were confronted with episodes of stigmatisation and discrimination. This resulted in more experiences of anger, isolation, withdrawal, frustration, feelings of being stigmatised, and internalisation of anti-LGBTI attitudes, as some participants perceived their 
sexuality as a sin and abnormal. The internalisation of anti-LGBTI attitudes, in other words, internalised homonegativity can have a devastating effect on the mental well-being of individuals. It is perceived as a significant correlate of substance use and misuse and suicide attempts and successful suicides (Sandy 2013), a view that is also reflected in this study. In addition to this association, the relationships between other mental health problems and human rights violations of LGBTI students are illustrated in Figure 1, entitled rights-impact conceptual model (RIM).

This model is not a statistical predictive tool, but rather a diagrammatic representation of categories of human rights, the processes of violation and the impact of these on the mental well-being of LGBTI people. The arrows in the model indicate the direction of the relationships between thematic clusters. This model indicates that social stress is the immediate determinant and primary predictor of mental health problems among stigmatised individuals, like LGBTI people. This means that the more this population is exposed to stressful social environments, the greater the impact on the mental well-being of its members.

\section{Study Implications}

Violation of the Human Rights of LGBTI individuals through discrimination and prejudice has implications for the mental well-being of the studied population. This population is often marginalised because of discriminatory practices in higher education institutions. Thus, frequent exposure to discriminatory practice, like denial of access to education and accommodation, and socialisation may result in the development of mental health problems, such as anxiety. Discrimination and prejudice are often associated with limited knowledge of LGBTI people. So, improving knowledge of LGBTI persons could be a necessary factor for combating discriminatory practices directed at this population. Combating discriminatory and prejudicial acts of the university community toward LGBTI students would be challenging given the multiplicity of influential factors, such as religious and cultural beliefs. Developing and implementing programmes for social change that focus on improving the university community's awareness of LGBTI individuals, may help improve attitudes toward this population. Because religious and traditional leaders play significant roles in influencing the university community's beliefs about LGBTI persons, it is also critical for the programme for social change to focus on changing attitudes of these leaders.

The discrimination and prejudice that LGBTI students face from university communities are the driving force for these students to hide their sexual orientation. The intention in this case is to protect themselves from the stresses of discrimination and prejudice, and possible mental 
health problems. It must be remembered that concealment itself has the potential of generating stress in individuals as well as preventing them from accessing formal and informal support services in LGBTI communities. Not seeking help may result in the development of further mental health problems. Taking this into account, the university management teams should create inclusive and safe environments that encourage LGBTI students to be open about their sexual orientation. Doing so would enable this population to develop a healthy gender and sexual identity that includes their sexuality, which might in turn contribute to their mental wellbeing.

\section{Conclusion and Recommendations}

Our results indicate that LGBTI students in a rural-based university are experiencing human rights violation from academic staff and heterosexual students. The discriminatory and prejudicial acts experienced by LGBTI students were mainly influenced by cultural and religious beliefs. Such experiences may result in victims experiencing mental health problems, a view also expressed by participants of this study. Approaches to avoid discrimination and stigmatisation were reported by participants. Some of these approaches, such as concealment, were reported by participants to cause mental health problems as well as acquisition of infections, like HIV. Thus, it is important for LGBTI students to be empowered through training to access alternative coping strategies. The university community also needs LGBTI awareness training. Doing so may result in a change in attitudes toward the LGBTI community, and promote social inclusion of this population in this setting.

\section{REFERENCES}

Arndt, M. and G. P. de Bruin. 2006. Attitudes toward lesbians and gay men: Relations with gender, race and religion among university students. Psychology in Society 33: 16-30.

Consolacion, T. B., S. T Russel and S. Sue. 2004. Sex, race/ethnicity, and romantic attractions: Multiple minority status. Adolescents and mental health, cultural diversity and ethnic minority psychology, Special Issue: Lesbian, gay and bisexual racial and ethnic minority individuals. Empirical Explorations 10(3): 200-214.

Dorington, R. E., L. F. Johnson, D Bradshaw and T. Daniel. 2006. The demographic impact of HIV/AIDS in South Africa: National and provincial indicators for 2006. Centre for Actuarial Research/ South African Medical Research Council. Cape Town: Actuarial Society of South Africa.

Epistein, D., S. Flynn and D. Telford. 2003. Masculinities and sexualities in schools and universities. Stoke-on-Trent: Trentham.

Guba, E. G. and Y. S. Lincoln. 1994. Competing paradigm in qualitative research. In Handbook of qualitative research, ed. K. D. Denzil and Y. S. Lincoln. Thousand Oaks, CA: Sage Publications.

Hogg, M. A. and D. T. Terry. 2000. Social identity and self-categorisation processes in organisational contexts. Academy of Management Review 25: 121-140

Human Rights Act. 1998. http://www.legislation.gov.uk/ukpga/1998/42/content (accessed 24 January 
2014).

Human Rights Watch. 2011. 'We'll show you you're a woman'. Violence and discrimination against black lesbians and transgender men in South Africa. Human Rights Watch: United States of America.

Hyayambwa, M. 2012. Homosexual rights and the law: A South African constitutional metamorphosis. International Journal of Humanity and Social Science 2(4): 50-58.

Langdridge, D. 2007. Phenomenological psychology: Theory, research and method. Harlow, UK: Pearson Education.

Lannutti, P. J. and K. A. Lachlan. 2007. Assessing attitude toward same-sex marriage. Journal of Homosexuality 53(4): 113-133.

Mabvurira, V., P. D. Motsi, T. Masuka and E. E. Chigondo. 2012. The 'politics' of sexual identities in Zimbabwe: A social work perspective. International Journal of Humanities and Social Sciences 2(13): 218-223.

Macnee, C. L. and S. McCabe. 2008. Understanding nursing research: Reading and using research in evidence-based practice. $2^{\text {nd }}$ Edition. Philadelphia: Lippincott Williams and Wilkins.

Mavhandu-Mudzusi, A. H. 2014. Experiences of lesbian, gay, bisexual, transgender and intersex students regarding sports participation in a South African rural based university. African Journal for Physical, Health Education, Recreation and Dance 20(2:2): 710-720.

Mavhandu-Mudzusi, A. H. and P. T. Sandy. 2015. Religion-related stigma and discrimination experienced by lesbian, gay, bisexual and transgender students at a South African rural-based university. Culture, Health \& Sexuality: An International Journal for Research, Intervention and Care. DOI: 10.1080/13691058.2015.1015614.

Meyer, I. H. 2007. Prejudice, social stress, and mental health in lesbian, gay, and bisexual populations: Conceptual issues and research evidence. Psychology Bulletin 129(5): 674-697.

Meyer, I. H., J. Dletrich and S. Schwartz. 2008. Lifetime prevalence of mental disorders and suicide attempts in diverse lesbian, gay and bisexual populations. American Journal of Public Health 98(6): 1004-1006.

Morris, J. S., L. DeGelder, L. Weiskrantz and R. G. Dolan. 2001. Differential exrageniculostriate and amygdala responses to presentation of emotional faces in a cortically blind field. Brain 124: 12411252.

Moskowitz, D. A., G. Rieger and M. E. Roloff. 2010. Heterosexual attitudes towards same-sex marriage. Journal of Homosexuality 57: 325-336.

Mudavanhu, J. 2010. The attitude of the Methodist church in Zimbabwe to homosexuality, towards a socio-sexological theological investigation. PhD thesis. College of Arts and Law. UK: University of Birmingham.

Mwamba, K. 2009. Attitudes and beliefs about homosexuality and same-sex marriage among a sample of South African students. Social Behaviour and Personality 37(6): 801-804.

Ould, P. J. and C. J. Whitlow. 2011. Same sex marriage and context-specific kinship terms. Journal of Homosexuality 58(8): 1085-1109.

Patel, M., T. F. Buss and R. Watson. 2003. Mitigating HIV/AIDS' Impacts on the civil service and teachers in Sub-Saharan Africa: Issue overview and strategy layout. A paper prepared on behalf of the National Academy of Public Administration's Africa Working Group for NAPA/USAID Conference on Mitigating HIV/AIDS'. Impacts on the Civil Service and Teachers in Sub-Saharan Africa held in Washington, DC, November 17-18.

Riggle, E., S. S. Rostosky, R. A. Prather and R. Hamrin. 2005. The execution of legal documents by sexual minority individuals. Psychology, Public Policy, and Law 11: 138-163.

Sandy, P. T. 2013. Motives for self-harm: Views of nurses in a secure unit. Journal of International Nursing Review 60(3): 358-365.

Sandy, P. T. and D. Shaw. 2012. Attitudes of mental health nurses to self-harm in secure forensic 
settings: A multi-method phenomenological investigation. Journal of Medicine and Medical Science Research 1(4): 63-75.

Sandy, P. T. and M. Rioga. Caring for the person with mental health needs in the community. In Community and public health nursing, ed. Sines et al., 2001-2021. $5^{\text {th }}$ Edition. Wiley Blackwell, UK.

Saucier, D. A. and A. J Cawman. 2004. Civil unions in Vermont: Political attitudes, religious fundamentalism, and sexual prejudice. Journal of Homosexuality 48(1): 1-18.

Smith, J. A. 2005. Semi-structured interviewing and qualitative analysis. In Rethinking methods in psychology, ed. J. A. Smith, R. Harre and L. van Langenhove. London: Sage.

Smith, J. A., P. Flowers and M. Larkin. 2009. Interpretive phenomenological analysis: Theory, method and research. London: Sage. 